సิ

SSCL-Preprint-522

November 1993

Distribution Category: 400

\title{
SSCL RFQ-DTL Matching Section Instrumentation
}

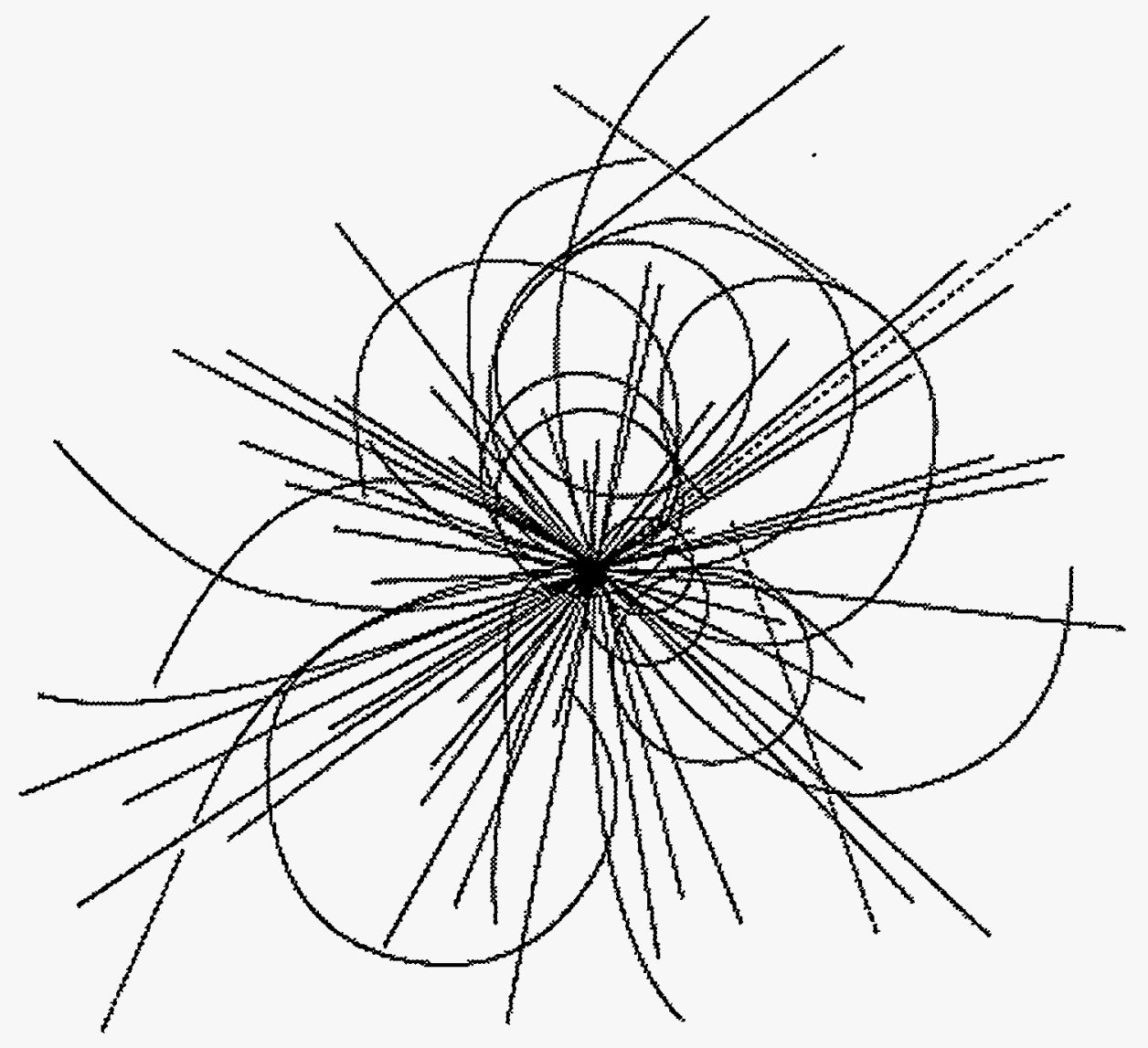

\section{Superconducting Super Collider Laboratory}

P. Datte

R. Aiello

M. Hayworth

R. Johnson

A. Jones

S. McClure

M. Mills

D. Martin

A. Ringwall

R. Webber

C. Yao
APPROVED FOR RELEASE OR O.R. PATENT GROUP PUBLIGFTION - O.R. PATET G. G.5... 


\section{Disclaimer Notice}

This report was prepared as an account of work sponsored by an agency of the United States Govemment. Neither the United States Government or any agency thereof, nor any of their employees, makes any warranty, express or implied, or assumes any legal liability or responsibility for the accuracy, completeness, or usefulness of any information, apparatus, product, or process disclosed, or represents that its use would not infringe privately owned rights. Reference herein to any specific commercial product, process, or service by trade name, trademark, manufacturer, or otherwise, does not necessarily constitute or imply its endorsement, recommendation, or favoring by the United States Government or any agency thereof. The views and opinions of authors expressed herein do not necessarily state or reflect those of the United States Govemment or any agency thereof.

Superconducting Super Collider Laboratory is an equal opportunity employer. 


\section{DISCLAIMER}

Portions of this document may be illegible in electronic image products. Images are produced from the best available original document. 
SSCL-Preprint-522

\title{
SSCL RFQ-DTL Matching Section Instrumentation
}

P. Datte, R. Aiello, M. Hayworth, et al.

\author{
Superconducting Super Collider Laboratory* \\ 2550 Beckleymeade Ave. \\ Dallas, TX 75237
}

November 1993

*Operated by the Universities Research Association, Inc., for the U.S. Department of Energy under Contract No. DE-AC35-89ER40486. 


\title{
SSCL RFQ-DTL MATCHING SECTION INSTRUMENTATION
}

\author{
P. Datte, R. Aiello, M. Hayworth, R. Johnson, A. Jones, S. McClure, M. Mills, D. Martin, A. Ringwall, \\ R. Webber, and C. Yao \\ Superconducting Super Collider Laboratory* \\ 2550 Beckleymeade Avenue, Dallas, Texas 75237 USA
}

\begin{abstract}
A description of the SSCL RFQ-DTL Matching Section instrumentation is presented with emphasis on design issues and early instrumentation commissioning results. The $\mathrm{H}^{-}$beam energy through the RFQ-DTL matching section is $2.5 \mathrm{Mev}$, the beam current is $27 \mathrm{~mA}$ with a pulse width of $35 \mu \mathrm{s}$. The typical beam diameter is $3 \mathrm{~mm}$. The instrumentation consists of three beam position monitors (BPM), a wire scanner, beam loss monitors (BLM), a slit and collector emittance measurement unit (EMU), a current toroid, and a Faraday cup. The instruments were designed to accommodate high current densities, have a large dynamic range with moderate bandwidths, and fit congested spaces.
\end{abstract}

\section{INTRODUCTION}

The SSC Linac ${ }^{1}$ consists of an ion source and three different accelerating structures. These include a radio frequency quadrupole (RFQ), a drift tube linac (DTL), and a coupled cavity linac (CCL). In principal, the first DTL tank can be connected directly to the RFQ. However, the RFQ and the DTL have different beam acceptance spaces, and the resulting mismatch would lead to emittance growth in the beam. Also, alignment differences between the RFQ and DTL could not be corrected, which again could lead to emittance growth. Given the stringent brightness requirements ${ }^{1}$ for the SSC Linac, it was deemed imperative to have a matching section to properly condition the beam from the RFQ into the first DTL. The RFQ-DTL matching section has three principle systems with which to accomplish this task. The first is the variable field permanent magnet quadrupole (VFPMQ) magnets for transverse focusing and beam steering. Second are double-gap RF buncher cavities for longitudinal phase space tuning, and the third is beam diagnostics to monitor the properties of the beam. The principle design challenge was to fit the above elements into an axial distance of only $540 \mathrm{~mm}$. The physics design ${ }^{2}$ and mechanical design ${ }^{3}$ of the matching section have been completed and have been discussed in previous papers. This paper will concentrate on the instrumentation mechanics used in the Matching Section. The instrumentation consists of three beam position monitors, a wire scanner, beam loss monitors, a slit and collector emittance measuring unit (EMU), a current toroid, and a Faraday cup. The instruments were design to accommodate high current densities, a large dynamic range with moderate bandwidth and congested spaces. Table I lists the instrumentation technical parameters of the RFQ-DTL matching section and Table II lists the BLM technical parameters. Table III lists the BPM technical parameters for the RFQ-DTL Matching Section.

*SSC Laboratory is operated by the Universities Research Association for the U.S. Department of Energy under Contract No. DE-AC35-89ER40486. 
Table I. Instrumentation Technical Parameters.

\begin{tabular}{lccccc}
\hline Instrumentation & Input Current & Bandwidth & Offset & Gain & Resolution \\
\hline Current Toroid & $25 \mathrm{~mA} \mathrm{Max}$ & $3.5 \mathrm{MHz}$ & $<1 \%$ & 160 & N/A \\
Wire Scanner & $250 \mu \mathrm{A}, 1 \mathrm{~mA}, 5 \mathrm{~mA}$ & $3.5 \mathrm{MHz}$ & $<1 \%$ & $1,4,20$ & $0.1 \mathrm{~mm}$ \\
Faraday Cup & $25 \mathrm{~mA} \mathrm{Max}$ & $3.5 \mathrm{MHz}$ & $<1 \%$ & N/A & $0.1 \mathrm{~mm}$ \\
EMU & $10 \mathrm{~mA} \mathrm{Max}$ & $3.5 \mathrm{MHz}$ & $<1 \%$ & $10^{3}$ & $0.1 \mathrm{~mm}$ \\
\hline
\end{tabular}

Table II. BLM Parameters for RQ-DTl Matching Section.

\begin{tabular}{lcc}
\hline Property & Value \\
\hline Sensitivity & $(\mathrm{E}=13.6 \mathrm{Mev})$ & $0.1 \%\left(1.5 \times 10^{10}\right) \mathrm{p} / \mathrm{s}$ \\
Dynamic Range & $10^{4}$ \\
Pulse Rise Time & $<1 \mu \mathrm{s} @ 0.1 \%$ sensitivity \\
\hline
\end{tabular}

Table III. BPM Technical Parameters.

\begin{tabular}{lcc}
\hline BPM Parameters & Requirement & Measured/Calculated \\
\hline Functionality & 2-Axis Position Sensor & 4 electrodes \\
Electrode Impedance & $50 \Omega$ & $50 \Omega \pm 1.5 \Omega$ \\
Absolute Accuracy & $<100 \mu \mathrm{m}$ & $250 \mu \mathrm{m}$ w/o correction \\
Aperture & $18 \mathrm{~mm}$ & $18 \mathrm{~mm}$ \\
$428 \mathrm{MHz}$ Signal Power & $>1 \mathrm{~mW} @$ Beam Center & $0.5 \mathrm{~mW} @ 25 \mathrm{~mA}$ \\
Position Sensitivity & - & $3.5 \mathrm{~dB} / \mathrm{mm}$ \\
Orthogonality Error & $<2 \% @ 50 \%$ Aperture & $\mathrm{TBD}$ \\
\hline
\end{tabular}

BEAM POSITION MONITOR

The RFQ-DTL Matching Section requires three BPMs for measuring the transverse displacement of the beam and its relative phase with respect to the buncher cavities. Figure 1 shows a typical BPM for the matching section.

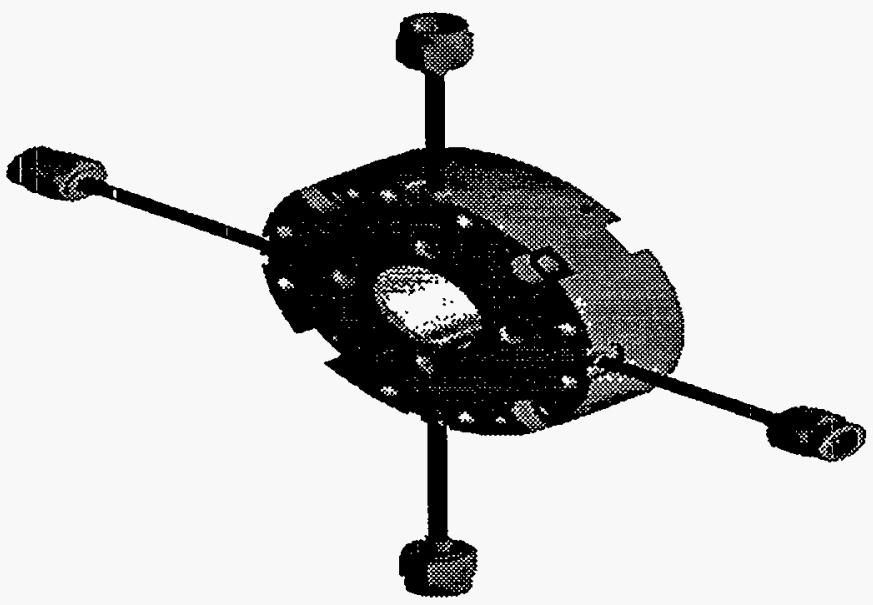

Figure 1. RFQ-DTl BPM Assembly. 
The RFQ-DTL BPM Detector is a compact 4-electrode stripline sensor. Each electrode is 6.6-mm long, subtends a $60^{\circ}$ angle, and is open-circuited at one end. So that electrode length could be maximized in the 10-mm long package, and to simplify mechanical support, the electrodes are fabricated by electrodepositing 0.08-mm thick copper onto a Macor ${ }^{\mathrm{TM}}$ annulus. Ceramic which is not copper plated is coated with a $100 \mathrm{~K} \Omega / \mathrm{sq}$. graphite loaded thick-film resin. The coating drains away stray charges deposited on the open ceramic. The detector body is a single block machined from type 304 stainless steel. Signals exit the BPM along 2.2-mm diameter $50 \Omega$ copper semi-rigid cables, insulated with PEEK plastic. The electrical center of each device is measured with respect to four precisely located $2-\mathrm{mm}$ holes. The BPM resides entirely in the Linac vacuum, so beam signals exit through double-ended SMA feedthrough connectors. Figure 2 shows sensitivity plots of a prototype RFQ-DTL BPM (4B0).

Sensibivity (CB) Map fơ Prototype BPM 4BO

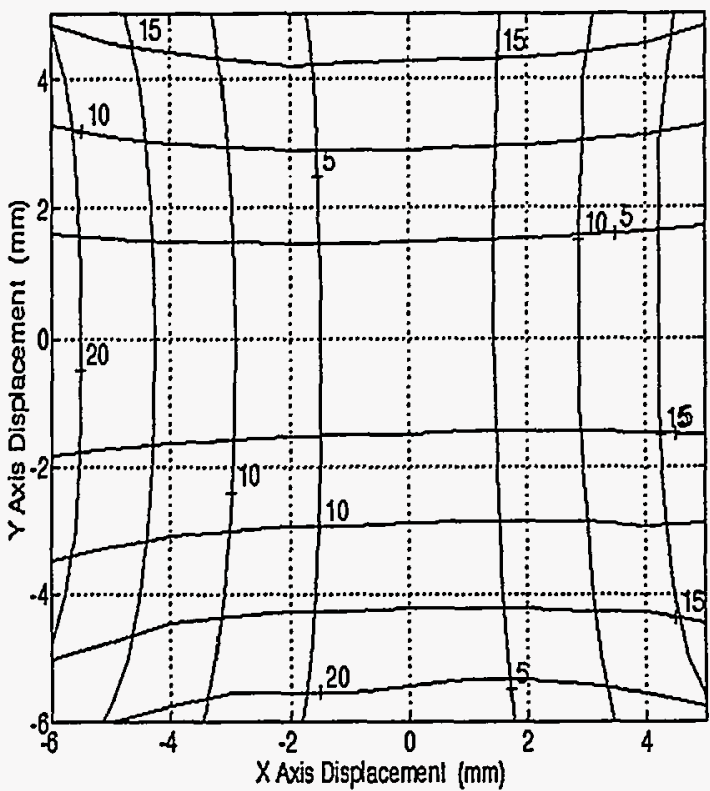

Sensitivity Function for Prototype BPM 480

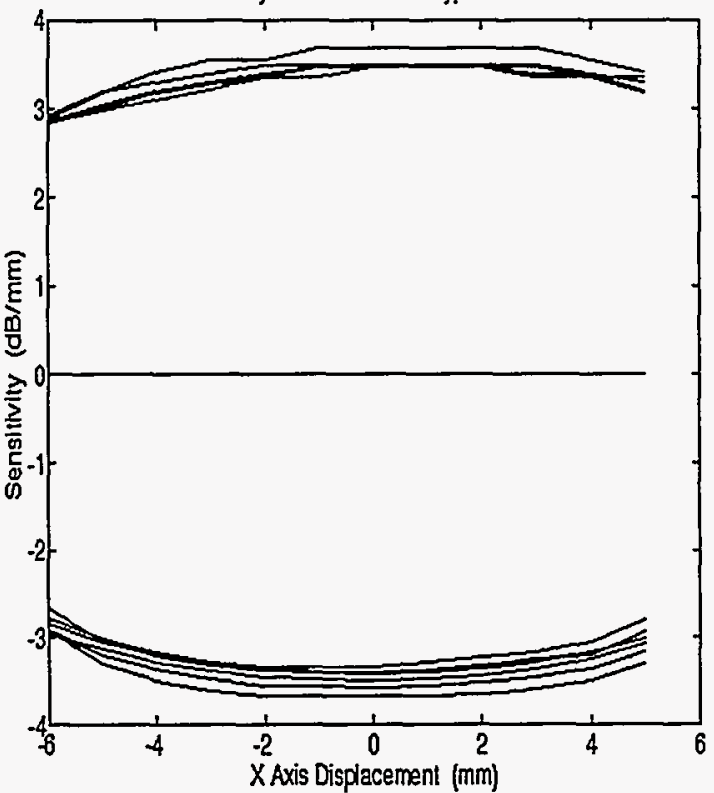

Figure 2. Sensitivity Plots for Prototype 4B0 RFQ-DTL Matching Section.

The test stand shown in Figure 3 was used to obtain the sensitivity data. It has been designed to measure the electrical sensitivity and electrical center of various BPMs in the linac.

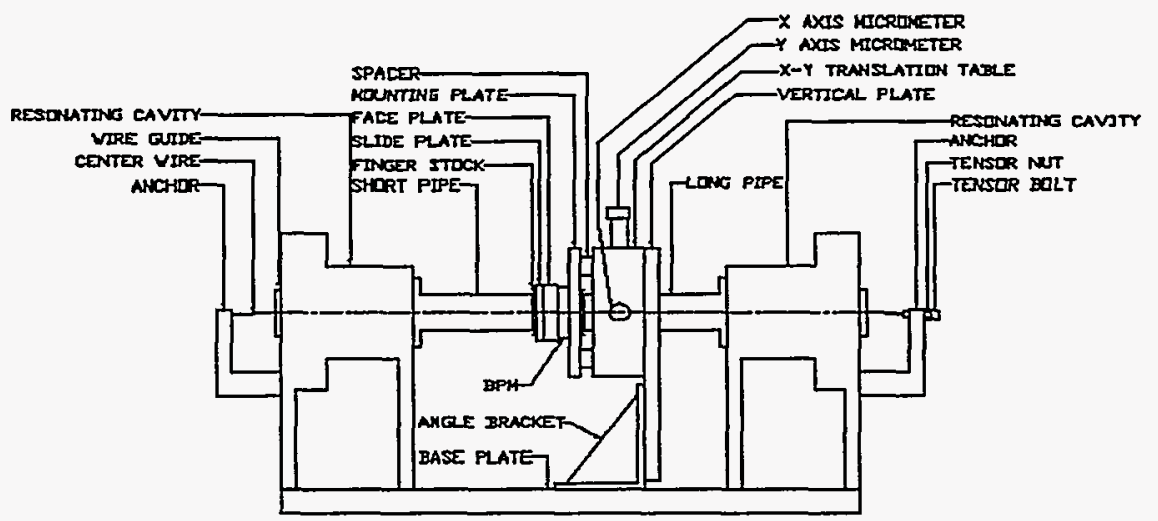

Figure 3. BPM Test Stand for Linac BPM Detectors. 
For testing, the BPM is mounted to a dual axis translation stage which allows independent micron size motion in both $\mathrm{X}$ and $\mathrm{Y}$ directions while maintaining $<80-\mu \mathrm{m}$ location tolerance. To simulate the beam, a wire is stretched through the center of the BPM and grounded at each end through a $428-\mathrm{MHz}$ $\pm 10 \mathrm{MHz}$ resonating cavity. By exciting the resonator and measuring the coupled power output of each BPM strip at various locations, a sensitivity plot can be made and the electrical center can be found. BPM signal processing is accomplished by a log-ratio technique. This technique is particularly effective because of the large dynamic range and excellent position linearity that can be achieved. A detailed description of this technique can be found in reference 4 .

\section{ACTUATED DEVICES}

Of the devices listed in Table I, four are actuated devices. They are the wire scanner, current toroid, Faraday cup, and the EMU. Each instrument consists of an actuator and instrument head, where the fundamental constituents of the actuator remain the same for each device. Figure 4 shows a typical instrumented actuator that is used for linac instrumentation.

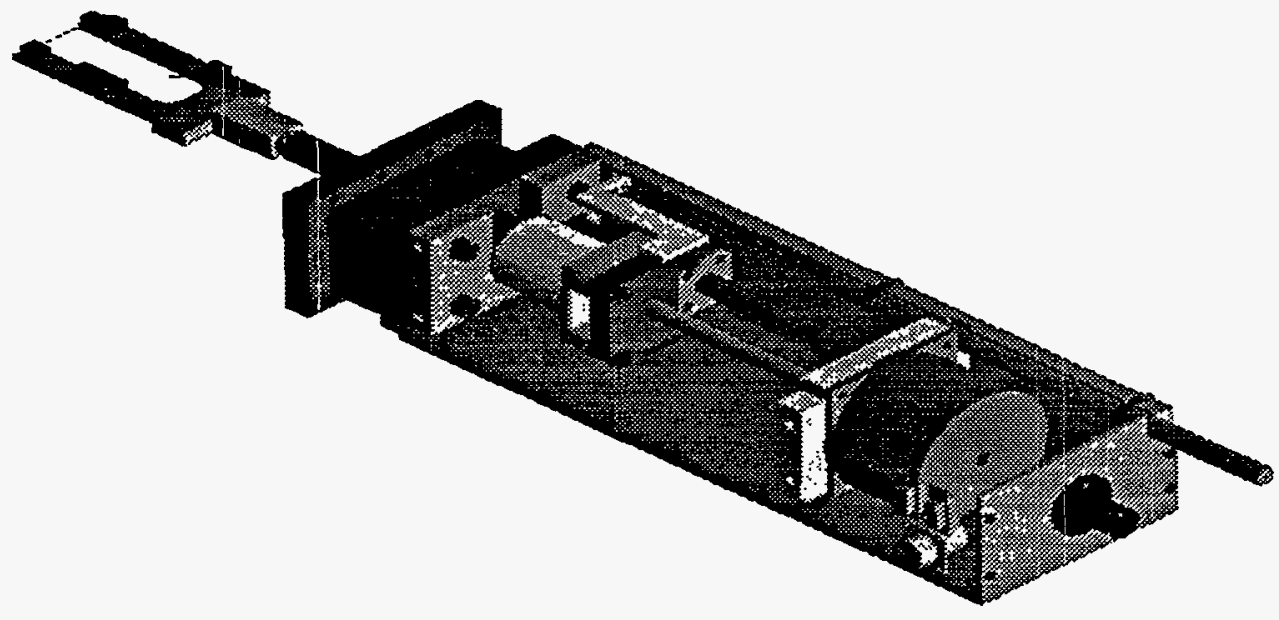

Figure 4. Standard Actuator System with Wire Scanner Head.

The motor is a linear actuator from Eastern Air Devices, Inc. ${ }^{5}$ model number LA34AGKS-2. This motor can produce a linear force up to $285 \mathrm{lbs}$. When microstepping is employed (1/50 th of a step) a resolution of $0.25 \mu \mathrm{m} / 1.8 \mathrm{deg}$ step can be achieved. A spline shaft that is aligned parallel with the lead screw maintains proper alignment throughout the travel. The actuator position may be determined in two ways, open loop (counting steps) or feedback through a position sensor. If the system is working correctly (i.e., no missing steps), the method of counting steps provides the most accurate positioning of the device. The position sensor, a Linear Variable Differential Transformer (LVDT), is mechanically connected to the actuator bellows assembly and moves with the sensing head. This method can provide reliable values on the order of $0.1 \mathrm{~mm}$ for nominal actuator stroke lengths of $100 \mathrm{~mm}$. To get the best performance from the position sensor the data should be fit to a line of the type $\mathrm{Y}=\mathrm{mX}+\mathrm{b}$. The "least- 
squares fit" is the suggested algorithm for this purpose. When the slope, $m$, of the least-squares line has been determined, it is possible to check the maximum deviation of linearity from the least-squares line by:

where

$$
\text { \%linearity }=\frac{\mathrm{Y}_{\mathrm{i}(\max )}-\mathrm{mX}_{\mathrm{i}}}{\mathrm{mX}_{\text {full }- \text { range }}} \times 100 \%
$$

$\mathrm{Y}_{\mathrm{i}(\max ;}$ - output voltage at the point of maximum deviation from best fit straight line.

$\mathrm{mX}_{\mathrm{i}}$ - point on best fit straight line corresponding to maximum deviation point.

Below are two graphs that describe the performance of the non-ratiometric LVDT position sensing device from Lucas Schaevitz with a 15-meter cable connected to an actuator. The first plot in Figure 5 shows a linear plot of the LVDT output vs. the stepper motor controller counter register.
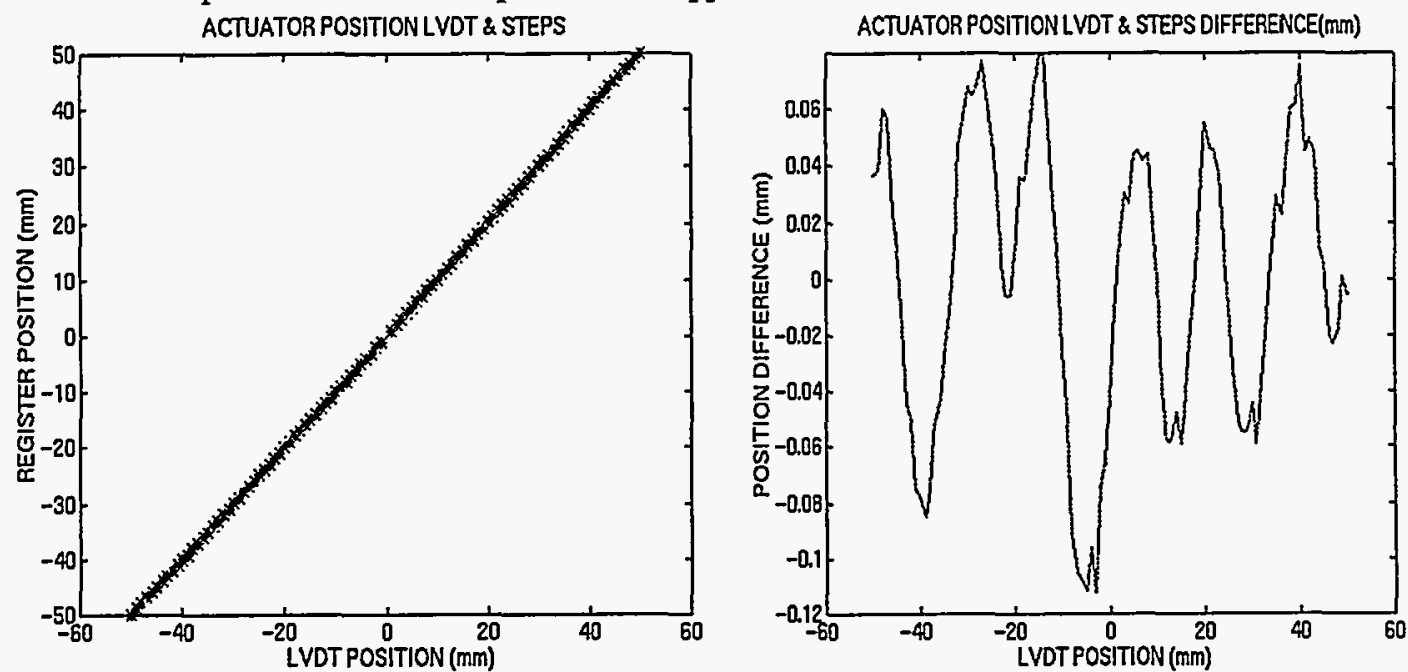

Figure 5. LVDT Readout vs. Step Count Register.

The second plot in Figure 5 shows the difference between the best fit line and the measured $Y$ values. From this plot it can be seen that the worst case difference value is on the order of $0.1 \mathrm{~mm}$. Presently the actuator system is used in the open loop mode and the position sensor (LVDT) is used mainly as a position verification at certain locations. The LVDT does not provide positional feedback information to the motor.

\section{CURRENT TOROID}

The beam current toroid (BCT) is located at the endwall of the RFQ-DTL Matching Section. Because of limited space the device is mounted on an actuator. The BCT is electrically identical to an actuated toroid at the exit of the RFQ. The two toroids are used to monitor the transmission through the RFQ-DTL matching section. The transformer is a 1-mil Supermalloy tape wound core from Magnetic Metals, Inc. model 44A8601, with a $\mu_{\mathrm{r}}$ (effective) $=2 \times 10^{5}$. The core is wound (50 turns) and potted (Shell Oil Co. 815/v40) into a piece of aluminum with a distributed $50 \Omega$ impedance and a sensitivity of 0.5 V/A. A single $50 \Omega$ loop is also included to deliver a calibrated test pulse when the system is operational. After installation and potting the bandwidth was measured to be on the order of $100 \mathrm{MHz}$ with a lowend cutoff frequency of $61 \mathrm{~Hz}$. Figure 6 shows a Bode plot of the BCT response and the actuated toroid head. 

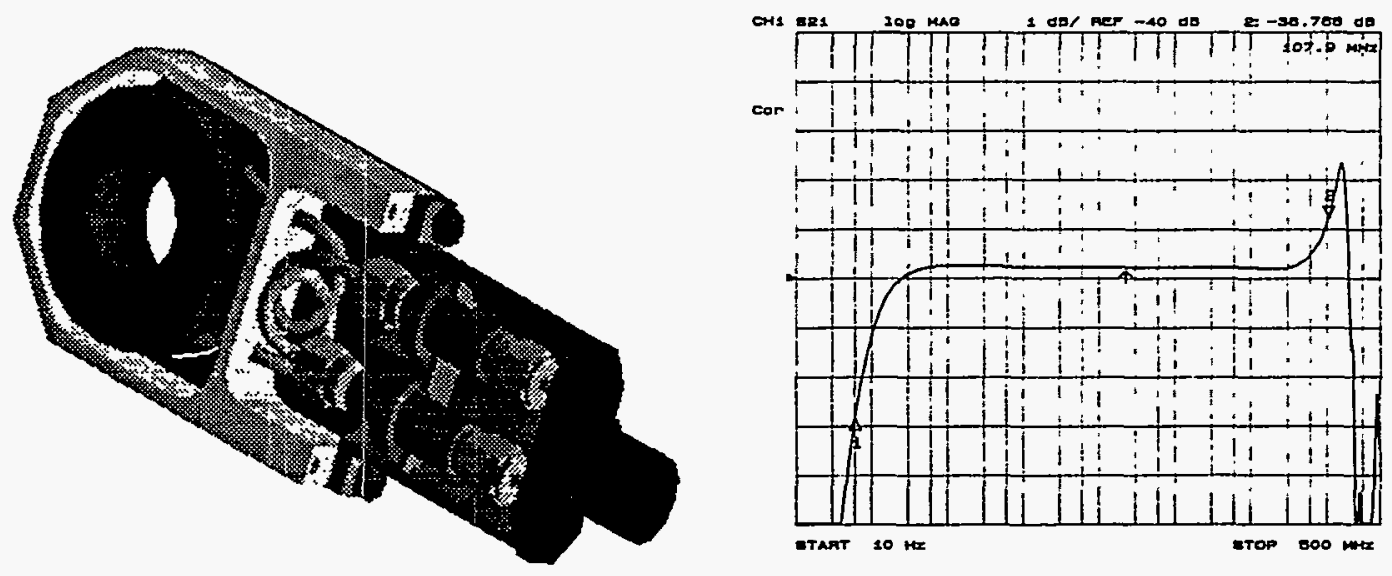

Figure 6. Bode Plot of Toroid Output and the RFQ-DTL Matching Current Toroid Head.

Table IV list the current toroid design parameters and the measured results.

Table IV. RFQ-DTL Matching Section Current Toroid.

\begin{tabular}{ccc}
\hline Parameter & Specification & Measured Result \\
\hline Beam Current (Max) & $50 \mathrm{~mA}$ & $>50 \mathrm{~mA}$ \\
Source Impedance & $50 \Omega$ & $50 \pm 2 \Omega$ \\
Sensitivity & $0.5 \pm 0.5 \%$ V/A @ $50 \Omega$ & $\pm 2 \%$ \\
Band Width & $5 \mathrm{kHz}-3.5 \mathrm{MHz}$ & $100 \mathrm{~Hz}-100 \mathrm{MHz}$ \\
Droop & $<3 \%$ in $35 \mu \mathrm{s}$ & $0.98 \%$ \\
EMI (electrostatic) & - & $-61 \mathrm{~dB} @ 1 \mathrm{kHz}$ \\
Clear Aperture & $\geq 16 \mathrm{~mm}$ & $17 \mathrm{~mm}$ \\
\hline
\end{tabular}

\section{FARADAY CUP}

The segmented Faraday cup has been designed to measure beam current and acts as a beam stop for beam entering the DTL. The device must pass through a vacuum chamber passage $20 \mathrm{~mm}$ in longitudinal length. The high instantaneous surface heat flux and the limited longitudinal space results in a very high surface temperature. For this reason the cup segments are graphite with a $40^{\circ}$ conical taper to reduce the surface heat flux. A finite surface element analysis yields a maximum surface temperature estimate of $1000^{\circ} \mathrm{C}$, see Figure 8 . The wide taper ensures that the beam always contacts a steep surface profile even when steered off center. The Faraday cup is fabricated by brazing a graphite cylinder to an electrically insulating ceramic base and then sectioning only the graphite into four quadrants. The sectioning is achieved by making two orthogonal wire EDM cuts through the graphite and angled to the longitudinal axis of the cup. The intersection of the two cuts forms a parallelepiped that is skewed to the beam axis such that the beam is always intercepted by the tapered graphite. The sectioning also provides electrical isolation and accommodates any thermal expansion. The brazement is then mounted into a water-cooled copper housing, and positioned on a jig with set screws. A cover plate secures the cup in position and provides pressure for the thermal contact. The signal cable is electrically connected through four Kovar pins which are brazed to the graphite segments on the back side of the housing. Fabrication drawings are presently being prepared for this device. Figure 7 shows the mechanical configuration of the Faraday cup. Table $V$ lists the beam parameters of the Faraday cup design. 
-IOMOd Ureәg әाЕาS

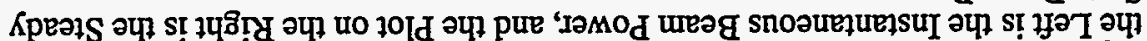

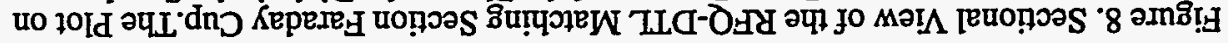
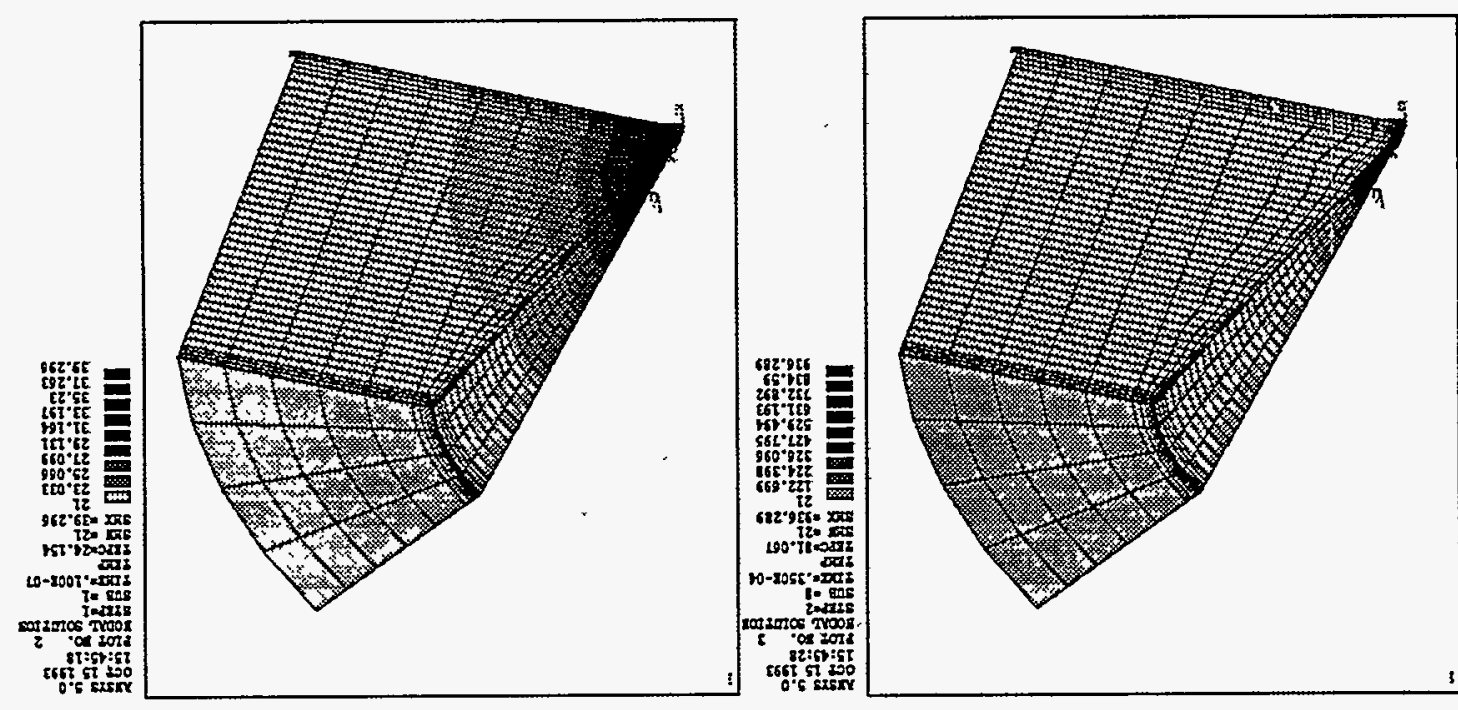

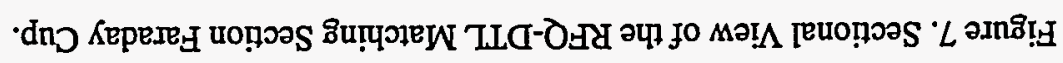

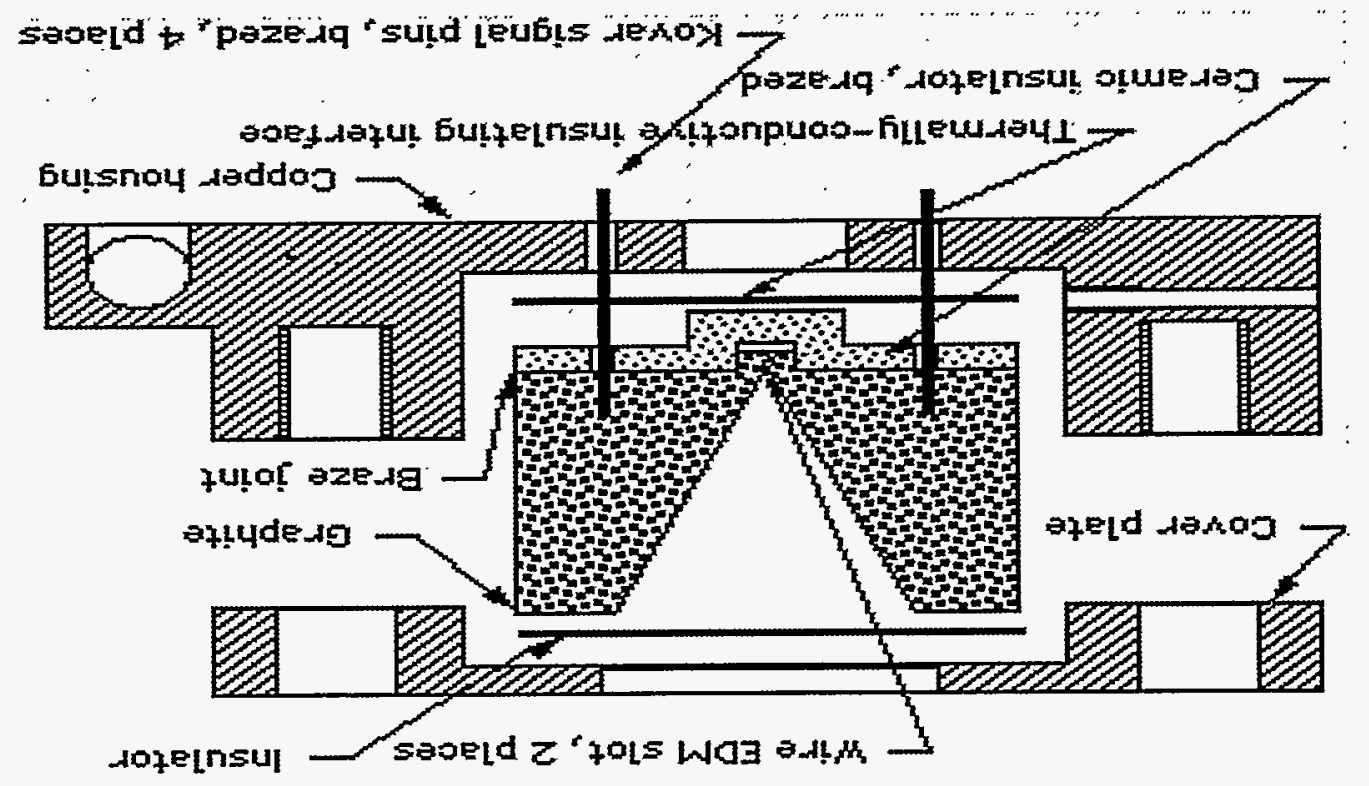


Table V. Faraday Cup Design Parameters.

\begin{tabular}{lc}
\hline ParaBeam Energymeters & Value \\
\hline Beam Energy & $2.5 \mathrm{Mev}$ \\
Beam Current & $25 \mathrm{~mA}$ \\
Pulse Width & $35 \mu \mathrm{s}$ \\
Repetition Rate & $10 \mathrm{~Hz}$ \\
Beam Size & $1 \mathrm{~mm} \mathrm{@} 1 \sigma$ \\
Average Power & $22 \mathrm{~W}$ \\
Instantaneous Power & $70 \mathrm{~kW}$ \\
Surface Temperature (Max) & $1000^{\circ} \mathrm{C}$ \\
\hline
\end{tabular}

\section{WIRE SCANNER}

The wire scanner head has been mechanically designed to pass through the beam at $45^{\circ}$ with respect to the vertical. As the wire passes through the beam, the signal current which is produced by proton interaction with the wire is measured by the electronics. By measuring the wire current and position at each location, a plot of the position versus intensity can be obtained ${ }^{6,8}$. The beam profile can be extracted from this plot. See Figure 9. The expected beam current can be calculated by determining the current density of the beam, the cross sectional area of the intercepting wire, and the secondary emission coefficient of the interaction at the energy of interest. The secondary emission results from low energy electrons emitted at the surface and $\delta$-electrons which are generated in a certain depth of the material depending on the energy and the angle of the incoming proton ${ }^{7}$. Table VI lists the RFQ-DTL matching section beam parameters that were used for the expected current and temperature calculations.

Table VI. RFQ-DTI Matching Section Beam Parameters for Wire Scanner.

\begin{tabular}{lc}
\hline Parameters & Value \\
\hline Energy & $2.5 \mathrm{MeV}$ \\
Secondary Emission Coefficient & $\varepsilon=0.25$ \\
Pulse Width & $35 \mu \mathrm{s}$ \\
Cycle Time & $0.1 \mathrm{~s}$ \\
Beam Size & $3 \mathrm{~mm}$ \\
Wire Diameter/Type & $0.0254 \mathrm{~mm} / \mathrm{W}$ \\
Beam Current & $25 \mu \mathrm{A}$ \\
Temperature & $\Delta \mathrm{T}=10^{4}{ }^{\circ} \mathrm{C}$ \\
\hline
\end{tabular}

Because the temperature is very high, the current density must be reduced in order to take a measurement without burning the wire. Future plans are to replace the tungsten wire with a graphite which has a lower $\mathrm{dE} / \mathrm{dX}$ than Tungsten. For a signal output, a 3 channel VME wire scanner preamplifier card is designed to be used with wire scanner heads that have up to three separate wires. Each channel produces $\pm 2 \mathrm{~V}$ output into $50 \Omega$ for input currents of $250 \mu \mathrm{A}, 1 \mathrm{~mA}$, and $5 \mathrm{~mA}^{6}$ (Table VII). 
Table VII. Wire Scanner Electronic Specifications.

\begin{tabular}{lc}
\hline Specification & Value \\
\hline Bandwidth & $10 \mathrm{MHz}$ \\
Input Impedance & $50 \Omega$ \\
Output Impedance & $5 \Omega$ \\
Gains & $1,4,20$ \\
Maximum Input & $12 \mathrm{~mA}$ \\
Full Scale Out (V) & $\pm 2 \mathrm{~V}$ into $50 \Omega$ \\
Offset & $<1 \%$ of Full Scale \\
Input Current Range & $250 \mu \mathrm{A}, 1 \mathrm{~mA}, 5 \mathrm{~mA}$ \\
\hline
\end{tabular}

The wire scanner data analysis program is designed for commissioning and operation of the Linac. It is designed as a X/Motif application and can be run on any UNIX workstation on the Linac control system network. It mainly consists of four functional parts: user interface, wire data display, $r m s$ beam width calculation, and emittance fitting. A main window with menu buttons, text window and drawing window which provides program control, message display and various plot functions. Display options are selected by menu buttons. The data display function is designed to directly show the acquired raw data. A three-dimensional view provides an overview of a complete scan. Several cross section views show the wave form from a single scan step or from a single longitudinal point. Data are also displayed in text format for detailed review and a data editor is also incorporated to allow the operator to eliminate outliers due to interferences or hardware failure. The analysis part of program extracts beam profile information (beam width, height and rotation angle) from the scan data and reconstructs the fitted beam profile. A wire data separation routine is first used to separate waveform signals from different wires of the wire scanner. Rms signal width for each wire is calculated assuming Gaussian beam distribution. For Gaussian beam, the transverse beam profile is defined by:

$$
\rho_{2}(x, y)=\int \rho_{4} e^{-X^{T} \sigma^{-1} X} d x^{\prime} d y^{\prime}
$$

where $X$ is four dimension phase space vector, $\sigma$ is transverse emittance matrix, $\rho 2, \rho 4$ are real space and phase space beam distribution. Wire signal is assumed to be proportional to the integral of the beam distribution $\rho 2$ along wire direction. Beam $\sigma$ information is obtained by fitting wire scan signal with this model. However, if the beam distribution is far away from Gaussian, the result could be wrong and another assumed distribution should be considered. Figure 9 is a typical output display of the data analysis program. This data was taken for the RFQ entrance wire scanner.
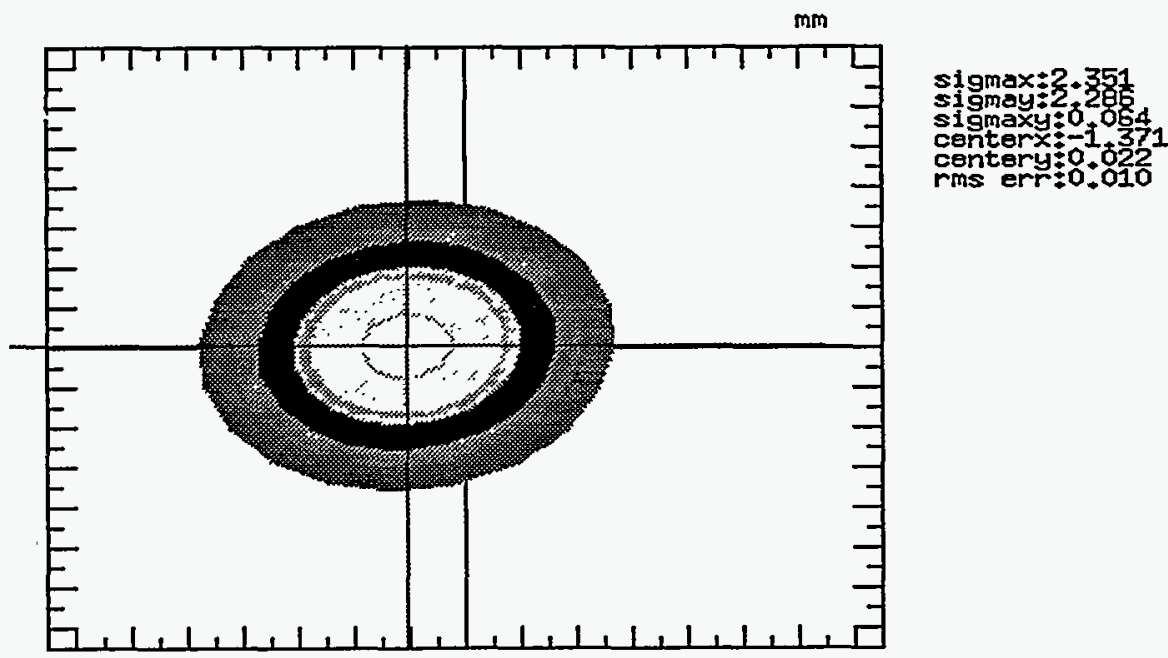

Figure 9. RFQ Entrance Wire Scanner Analysis. 


\section{BEAM LOSS MONITOR}

The requirements which have been established for the linac impose some unique properties on the BLM system because the linac is unique in the accelerator chain. In terms of the response times of detectors, i.e., $\mu \mathrm{s}$, the linac is the only accelerator for which the pulse structure of the beam is important. The linac also spans the largest relative energy range and of particular importance to the BLM detectors the energy starts near zero. Finally, since the secondary radiation from beam loss is directed forward, it is somewhat more difficult to detect in a linear as opposed to a circular accelerator. For a detailed description of the BLM for the RFQ-DTL matching section please refer to "Beam Loss Monitor System For The SSC," R.G. Johnson and N.V. Mokhov these proceedings.

\section{EMITTANCE MEASUREMENT UNIT}

The EMU is being designed to measure the transverse emittance at the output of the RFQ. The slit and collector will be oriented at $45^{\circ}$ to the vertical and will scan both $\mathrm{X}$ and $\mathrm{Y}$ axis with a single actuator ${ }^{7}$. The silt will be manufactured similar to the Faraday cup because of the beam that power exists in this area. The 128 collectors will be made of copper foils $0.0254-\mathrm{mm}$ thick and will be spaced $0.05 \mathrm{~mm}$ apart with Mica paper. The design is $50 \%$ complete and will be ready for commissioning by April.

\section{SUMMARY}

The BPM, current toroid, wire scanner, and BLM have completed designs and are now in the testing stage. The wire scanner and current toroid, and Faraday cup electronics have been is use at the RFQ for over a year now and have been commissioned. The early results of the BPM look good and the best three prototypes will be used in the matching section. The BLMs are ready to be purchased in production quantity and no major problems are anticipated. The water-cooled Faraday cup is of moderate risk because of the high current density of the beam. This is also true for the slit. The commissioning of the these two devices may require reduced beam power.

\section{REFERENCES}

1. L.W. Funk, "The SSC Linac," 1992 Linear Accelerator Conference Proceedings, Vol. 1, pp. 8-12.

2. R. C. Sethi et al., "Design of the RFQ-DTL Matching Section," 1992 Linear Accelerator Conference Proceedings, Vol. 2, pp. 483-485.

3. A. D. Ringwall and C. M. Combs, "SSCL RFQ to DTL Input Matching Section," 1992 Linear Accelerator Conference Proceedings, Vol. 1, pp. 235-237.

4. G. Roberto Aiello, Mark R. Mills, "Log-Ratio Technique for Beam Position Monitor Systems," AIP Conference Proceedings No. 281, Particles and Fields Series 52. Accelerator Instrumentation Fourth Annual Workshop, Berkeley, CA, pp. 301-310 (1992).

5. Eastern Air Devices, Inc., 1 Progress Drive, Dover, New Hampshire 03820.

6. P. Datte et al., "Beam Instrumentation for the SSC RFQ," Presented at the 1993 IEEE Particle Accelerator Conference on May 17 - 20, Washington, D.C.

7. Oscar R. Sander, "Transverse Emittance: Its Definition, Applications, and Measurement," AIP Conference Proceedings No. 212, Accelerator Instrumentation, Upton, NY, pp. 143144 (1989).

8. M. C. Ross et al., "Experience With Wire Scanner At SLC," AIP Conference Proceedings No. 281, Particles and Fields Series 52. Accelerator Instrumentation Fourth Annual Workshop, Berkeley, CA, pp. 264-269 (1992). 